\title{
Acute Renal Failure in the Neonate
}

\author{
Jean-Pierre Guignard ${ }^{1} \quad$ Uma S. Ali ${ }^{2}$ \\ ${ }^{1}$ Department of Pediatrics, CHUV, Lausanne University, Medical \\ School, Lausanne, Switzerland \\ 2 Nephrology Division and PICU, BJ Wadia Hospital for Children, \\ Mumbai, Maharashtra, India \\ J Pediatr Intensive Care 2016;5:42-49.
}

\begin{abstract}
\section{Keywords}

- neonatal nephrology

- neonatal renal failure

- asphyxic renal failure

- nephrotoxic drugs

Acute renal failure (ARF) is a common disorder in high-risk neonates. ARF may be oliguric or nonoliguric, the latter having a better prognosis. Risk factors for ARF include prematurity, respiratory and vascular disorders, heart failure, congenital uropathies, and the use of nephrotoxic drugs. Chemical analysis of urine and ultrasounds help differentiate the nature and the type of ARF: prerenal, intrinsic, or postrenal. Conservative management of prerenal forms of ARF consists in carefully restoring cardiac output and controlling fluid and electrolyte balances. Early relief of obstruction is mandatory in severe postrenal forms of ARF. Renal replacement therapy is often necessary when ARF is secondary to intrinsic renal damage: peritoneal dialysis is the treatment of choice. Hemodialysis and continuous venovenous hemofiltration may be used in specific cases. Overall prognosis of ARF depends on the nature and severity of the renal injury that has led to renal failure.
\end{abstract}

\begin{abstract}
Address for correspondence Jean-Pierre Guignard, MD, Lausanne University, Medical School, 1011 Lausanne, Switzerland

(e-mail: jean-pierre.guignard@unil.ch).
\end{abstract}

\section{The Developing Kidney}

The fetal kidney does not have real homeostatic responsibilities; it starts producing urine around the 12th week of gestation. This urine represents a great part of the amniotic fluid. Nephrogenesis is complete by 35 weeks of gestation. GFR at birth is close to $20 \mathrm{~mL} / \mathrm{min} / 1.73 \mathrm{~m}^{2}$ in term neonates ${ }^{1}$ and reaches $50 \mathrm{~mL} / \mathrm{min} / 1.73 \mathrm{~m}^{2}$ at 4 weeks of life. It is

\section{Introduction}

Acute renal failure (ARF) is due to a sudden decrease in glomerular filtration rate (GFR) with consequent retention of nitrogen waste products and disturbances in water, elecspecifics, the premature fetal and neonatal kidneys are particularly prone to develop ARF. The term acute kidney injury (AKI) is now often used instead of ARF. But while kidney injury can lead to renal failure, the latter can occur without kidney injury, as for instance, in conditions of prerenal failure. The causes of ARF (-Table 1) can be prerenal (functional), renal (intrinsic), and postrenal (obstructive).

received

July 31,2014 accepted after revision

September 15, 2014

published online

October 19, 2015 somewhat lower in premature neonates. ${ }^{2}$ GFR shows a progressive direct correlation with both gestational and postnatal ages. ${ }^{3,4}$ In healthy premature neonates, nephrogenesis continues after birth, but for only 40 days. ${ }^{5}$ Nephrogenesis stops at birth in growth-retarded neonates. Lowbirth-weight infants have consequently a lower number of nephrons as compared with term infants.

\section{Definition}

Acute renal failure (ARF) can be oliguric or nonoliguric, so urine flow rate cannot define ARF whose diagnosis is based on the follow-up of the plasma creatinine concentration. ARF is suspected when the plasma creatinine is greater than $130 \mu \mathrm{mol} / \mathrm{L}$ $(15 \mathrm{mg} / \mathrm{L})$ for at least 24 to 48 hours while maternal renal function is normal. ${ }^{6}$ In very premature neonates, the elevated plasma creatinine present at birth increases in the first 3 to 4 days of life because of tubular reabsorption of creatinine across the leaky tubules. ${ }^{3}$ In clinical practice, repeated measurements of plasma creatinine are used to confirm the presence of ARF. Oliguria is defined by urine output less than $1.0 \mathrm{~mL} / \mathrm{kg} / \mathrm{h}$ in preterm and less than $0.5 \mathrm{~mL} / \mathrm{kg} / \mathrm{h}$ in term neonates.
Issue Theme Nephrology in Pediatric Critical Care; Guest Editors: Eunice John, MD, Dch, FAAP, and Gokhan Olgun, MD
Copyright $\odot 2016$ by Georg Thieme Verlag KG, Stuttgart · New York
DOI http://dx.doi.org/ 10.1055/s-0035-1564735. ISSN 2146-4618. 
Table 1 Causes of acute renal failure in neonates

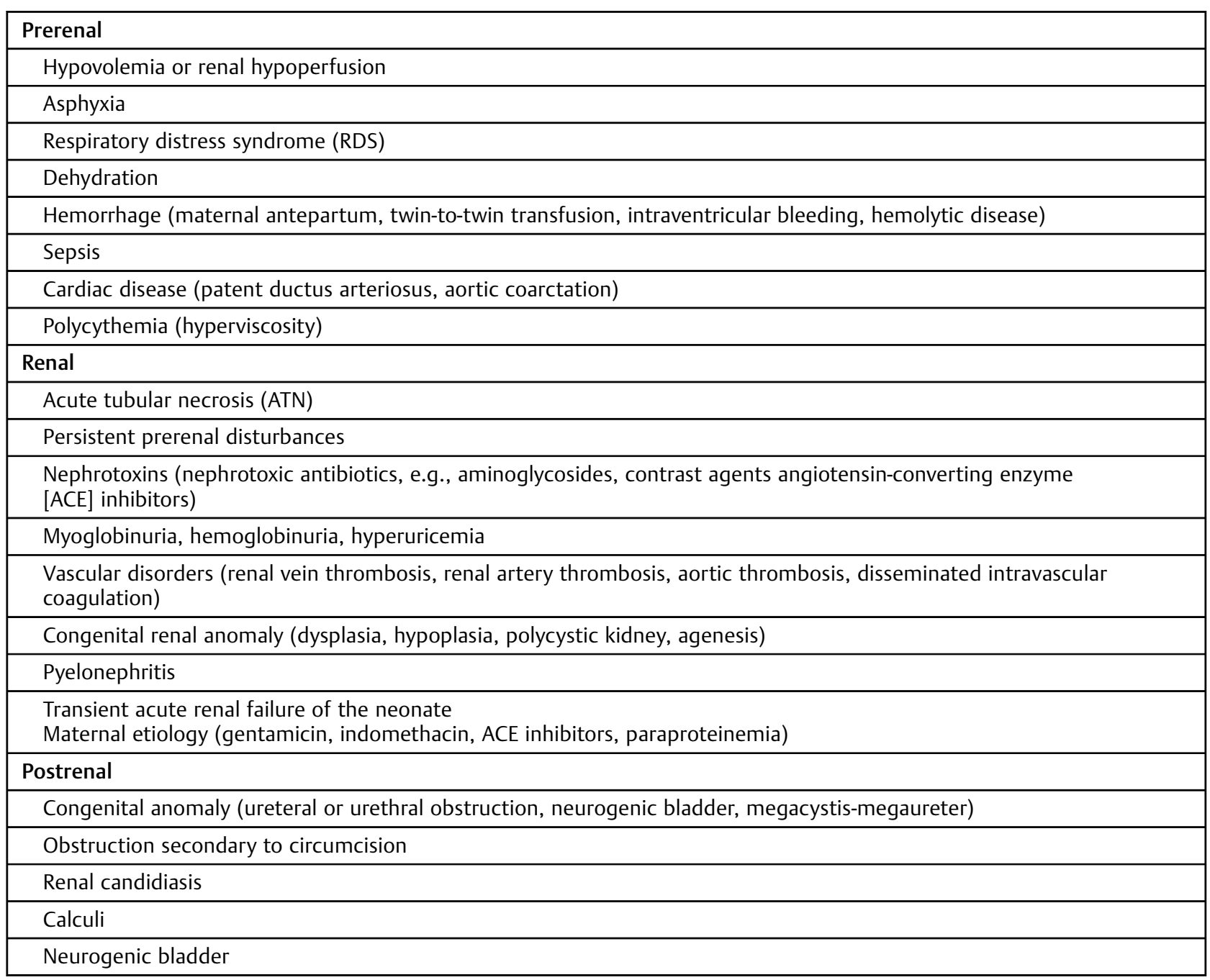

\section{Etiology and Pathogenesis}

\section{Etiology}

Factors responsible for the occurrence of ARF are listed in -Table 1. Intrinsic renal failure accounts for less than $10 \%$ of the cases and may occur due to drug-induced nephrotoxicity or when the hypoxic-ischemic insults are prolonged or severe. ${ }^{4,7-9}$

\section{Prerenal Causes}

More than $75 \%$ of cases of neonatal renal failure are prerenal in nature. All factors that decrease cardiac output can lead to renal insufficiency. Hypotension, hypoxemia, disturbances in acidbase balance, and administration of vasoconstrictive agents are common stresses that increase the renal vascular resistance. ${ }^{7}$ Cardiac diseases, the persistence of patent ductus arteriosus, and hyperviscosity states can also impair cardiac output.

\section{Intrinsic Causes}

When persisting, prerenal disturbances can lead to acute renal necrosis and severely impair renal function. ${ }^{9}$ The renal parenchyma can also be injured by vascular disorders, renal thrombosis, nephrotoxins, acute pyelonephritis, myoglobinuria, and hemoglobinuria. Cortical necrosis may result from severe ischemia and microthrombi formation. Congenital renal anomalies, including hypoplasia, dysplasia, and cystic diseases, can favor the occurrence of ARF.

\section{Postrenal Causes}

Obstruction on the urinary tract, whatever the cause, can lead to ARF. The obstruction can occur at the level of the ureters, the bladder, or the urethra. When not relieved rapidly, the obstruction can induce permanent damage to the kidney.

\section{Nephrotoxic Drugs}

Nephrotoxic drugs can affect the fetus when administered to the pregnant mother, or the neonate when administered postnatally. ${ }^{8}$ Aminoglycosides may cause renal injury even with normal blood levels due to the high tissue concentrations of the drugs that can be achieved. All cephalosporins are potentially nephrotoxic though clinically the third generation appears to be reasonably safe. Vancomycin needs to be used in 
appropriate dosages and monitored closely. The use of two simultaneous nephrotoxic drugs should preferably be avoided. Vasoactive drugs interfering with the synthesis of prostaglandins as well as with the renin-angiotensin system are particularly deleterious to the immature kidney. ${ }^{10,11}$

\section{Nonsteroidal Anti-inflammatory Drugs}

The maintenance of prenatal and postnatal GFR is highly dependent on prostaglandin-mediated afferent arteriolar dilation. ${ }^{7}$ Inhibition of prostaglandins can lead to severe fetal or neonatal failure that can even be irreversible. ${ }^{10}$ Administration of nonsteroidal anti-inflammatory drugs (NSAIDs) early in pregnancy carries a high risk of inducing renal tubular dysgenesis in the fetus, with fetal oliguria and oligohydramnios. All cyclo-oxygenase (COX) inhibitors, including the COX-2 selective, can harm the developing kidney. ${ }^{10}$ When really needed, all NSAIDs must be used with great caution, be it before or after birth.

\section{Angiotensin Inhibitors, Angiotensin-Converting Enzyme Inhibitors, and Angiotensin II AT1 Receptor Blockers Maternal ingestion of angiotensin-converting enzyme inhib- itors (ACEIs) and angiotensin II AT1 receptor blockers (ARBs) produces a classic fetopathy with renal tubular dysgenesis. ${ }^{11}$ It can also result in a dramatic fall in GFR leading to fetal oliguria, oligohydramnios, and postnatal oliguric renal failure that can be irreversible. Postnatal administration of drugs interfering with the action of angiotensin II can also depress GFR and lead to renal failure. Drugs interfering with angio- tensin II must definitively be avoided during pregnancy and used with caution after birth. ${ }^{11}$}

\section{Specific Pathogenesis}

Hypoxemic-hypoxic insults and sepsis are the major stresses that can induce renal failure by the activation of vasoactive factors and inflammatory agents. ${ }^{9}$

\section{Clinical Events}

Bilateral renal agenesis, multicystic dysplastic kidneys, autosomal recessive polycystic kidneys, and obstructive uropathies can all lead to oligohydramnios. Late-onset oligohydramnios is a characteristic finding in renal tubular dysgenesis and warrants a thorough evaluation for exposure to drugs such as NSAIDs, ACEIs, and ARBs.

Mechanical ventilation reduces the preload by increasing the intrathoracic pressure and results in decreased cardiac output and renal perfusion. ${ }^{12}$ Umbilical artery and vein catheterization can lead to renal artery or renal vein thrombosis. Indwelling urinary catheters favor the occurrence of urinary tract infections (UTIs), and the use of broad-spectrum antibiotics may result in the development of fungal UTIs and fungal bezoars.

\section{Physical Features}

The presence of external features such as Potter's facies, preauricular tags, polydactyly, single umbilical artery, or sacral abnormalities may indicate the presence of an underlying developmental renal anomaly. Enlarged kidneys may indicate autosomal polycystic renal disease or obstructive uropathy. Palpable bladder and a poor stream of urine in a male child suggest the presence of posterior urethral valves. All these congenital uropathies can damage the developing kidney and lead to severe long-term consequences. ${ }^{13}$

Edema due to fluid overload, hypoproteinemia, or capillary leak may complicate the clinical course. Hypotension due to hypovolemia, sepsis, or cardiac dysfunction may coexist. Hypertension due to renal failure may be encountered during the course of illness as a result of volume overload or a high renin state. Recognition of hypertension requires reference to appropriate charts as the normal range of blood pressure in neonates will vary depending on gestational age, weight, and postnatal age. ${ }^{14}$

\section{Oliguric Acute Renal Failure}

Approximately $30 \%$ of normal newborns void soon after birth; $92 \%$ will void within the first 24 hours and $99 \%$ by 48 hour. Oliguria is observed in most neonates presenting with ARF. It can also result from poor fluid intake or be due to inappropriate antidiuretic hormone (ADH) secretion in sick neonates.

\section{Nonoliguric Acute Renal Failure}

Up to one-third of neonates with ARF may have nonoliguric renal failure that can only be detected by the finding of elevated serum creatinine or cystatin C levels. Birth asphyxia, aminoglycoside therapy, and methoxyflurane anesthesia are some of the conditions leading to nonoliguric renal failure. $^{15}$

\section{Laboratory Evaluation}

\section{Urinalysis}

Urinalysis in prerenal failure may show normal urine, epithelial cells and coarse granular casts, mild proteinuria, and microscopic hematuria. Gross or microscopic hematuria is usually seen in renal vein thrombosis and sometimes in UTIs. Pus cells or pus cell casts reflect severe UTIs.

\section{Blood Count}

Anemia is present in neonates with ARF, in whom it may also reflect bleeding or dilution by fluid retention. Eosinophilia suggests an allergic reaction to drugs.

\section{Urea}

Plasma urea is a poor marker of renal function as it is influenced by multiple factors such as protein intake, urine output, gastrointestinal bleeding, and a hypercatabolic state. It may be deceptively low in sick neonates as a result of poor protein intake.

\section{Creatinine}

Plasma creatinine is the most widely used marker of GFR. The serum creatinine in the first few days of life reflects maternal creatinine levels and gradually comes down to normal neonatal levels close to $4 \mathrm{mg} / \mathrm{L}(35 \mu \mathrm{mol} / \mathrm{L}$ ) by 1 week of age in term infants. In preterm babies the creatinine may actually rise further before falling slowly to normal neonatal levels over 2 to 3 weeks. ${ }^{1}$ 
Failure of plasma creatinine to decrease below the maternal level after the first few days of life or a rise in serum creatinine greater than 25 to $30 \mu \mathrm{mol} / \mathrm{L}$ ( $3 \mathrm{mg} / \mathrm{L}$ ) per day is indicative of $\mathrm{ARF}^{6}$ Creatinine levels may also be artifactually elevated, depending on the associated comorbid conditions as well as the methodology used for its estimation. In the commonly used Jaffe's method that also measures noncreatinine chromogens, creatinine levels may be spuriously high in the presence of hyperbilirubinemia or treatment with cephalosporins. However, the use of newer techniques such as the kinetic or enzymatic assays does not measure these chromogens and give truer values of creatinine. Further improvement in measuring creatinine has recently been achieved by the use of newer techniques such as the highperformance liquid chromatography and the gas chromatography-isotope dilution mass spectrometry. ${ }^{1}$

\section{Cystatin C}

Plasma cystatin C has been used to estimate GFR. It is freely filtered, almost completely reabsorbed, and catabolized by proximal tubular cells. Its clearance can consequently not be calculated. The clinical use of this marker suffers important drawbacks: (a) the handling of this product by the immature tubular cells, in particular when their injury is not known; (b) its production and concentration are influenced by factors independent of GFR, such rises in serum protein C-reactive levels, thyroid dysfunction, or corticosteroid administration; and (c) its measurement is considerably more expensive than that of creatinine, by a factor of at least 12 . $^{1}$ That plasma cystatin C is a better marker of GFR (or an earlier marker of AKI) than creatinine is questionable and has not yet been clearly demonstrated.

\section{Urinary Indices}

Chemical analysis of urine may help distinguish prerenal from intrinsic ARF. Previously healthy kidneys respond to acute hypoperfusion by maximally conserving water and electrolytes, thus excreting concentrated urine with low sodium concentration $\left(\mathrm{U}_{\mathrm{Na}}\right)$. Therefore a urinary osmolality $\left(\mathrm{U}_{\mathrm{osm}}\right)$ greater than $400 \mathrm{mOsm} / \mathrm{kg} \mathrm{H}_{2} \mathrm{O}$, a $\mathrm{U}_{\mathrm{Na}}$ less than 40 $\mathrm{mmol} / \mathrm{L}$, and a fractional excretion of sodium $\left(\mathrm{FE}_{\mathrm{Na}}\right)$ less than $2 \%$ suggest the presence of prerenal functional insufficiency. By contrast, an intrinsically damaged kidney is not able to concentrate urine and retain sodium. It should be noted that these urinary indices are only valid when measured before the administration of volume expanders or diuretics, and that they cannot be used in very premature salt-wasting neonates who may "normally" present with $\mathrm{FE}_{\mathrm{Na}}$ greater than $5 \%{ }^{1,7}$

\section{Biomarkers of Acute Kidney Injury}

The most promising novel biomarkers of early injury include plasma neutrophil gelatinase-associated lipocalin (NGAL) and urine interleukin 18, NGAL, and kidney injury molecule 1 (KIM-1). These markers are presently under investigation in neonates. ${ }^{16,17}$

\section{Imaging}

Ultrasound examination of the genitourinary tract is useful for assessing the size, the shape, and the echogenicity of the kidneys; for diagnosing pelvic-calyceal dilation; and for examining the ureters and the bladder. Imaging gives highly valuable diagnostic information. Evaluation of the renal vessels by color Doppler gives important information regarding the presence of renal vein or renal arterial thrombosis. Radionuclear scan utilizing various isotopes may help differentiate the causes of ARF. Voiding cystourethrography is useful to identify lower urinary tract obstruction (posterior urethral valves).

\section{Conservative Management of Acute Renal Failure}

\section{Management of Suspected Prerenal Oliguric Acute Renal Failure}

Regular monitoring of urine output and serial measurements of serum creatinine allow the early detection of renal insufficiency. Analysis of the urinary indices is mandatory to define the type of ARF (Fig. 1).

\section{Fluid Challenge and Rehydration}

In the prerenal types of ARF, volume expansion by the administration of $20 \mathrm{~mL} / \mathrm{kg}$ of normal saline over 1 to 2 hours usually improves urine output. Such an administration should not be given when there is clinical evidence of fluid overload. In neonates with fluid refractory hypotension, dopamine infusion should be started to improve blood pressure and renal perfusion. Low-dose hydrocortisone may be useful in fluid and dopamine refractory hypotension. $^{18}$

\section{Low-Dose Dopamine}

The use of low-dose dopamine $(2.5-5.0 \mu \mathrm{g} / \mathrm{kg} / \mathrm{min})$ in preterm babies with hyaline membrane disease has been claimed to improve renal blood flow, natriuresis, and diuresis, and produce a modest improvement in renal function. ${ }^{19}$ Dopamine can have several adverse effects such as tachycardia, cardiac arrhythmia, and increased pulmonary vascular resistance. The modest benefits that may be obtained in some babies with low-dose dopamine have to be weighed against the possible adverse effects of the drug. All neonatal studies in favor of the "renal" doses of dopamine were uncontrolled, and a placebo-controlled randomized study in adult patients failed to demonstrate that low-dose dopamine could protect the stressed kidney. ${ }^{20}$

\section{Furosemide}

When urine output fails to improve after fluid repletion, a trial of loop diuretics can be given. Intravenous furosemide at 1 to $3 \mathrm{mg} / \mathrm{kg}$ may improve the diuresis. The natriuretic and diuretic responses to furosemide are highly variable and depend on the level of GFR. When a diuretic response is present, it carries the risk of inducing hypovolemia. Clearly, loop diuretics basically should not be used to treat oliguric neonates, but primarily those presenting with edematous states and congestive heart failure. ${ }^{21}$ When given in association with dopamine, furosemide has been claimed to have a synergetic effect in increasing urine output. 


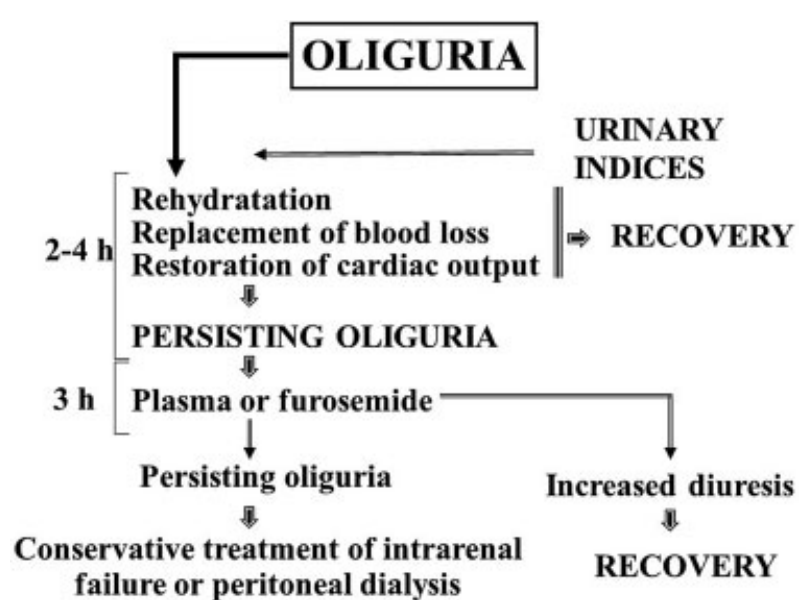

Fig. 1 Management of oliguric acute renal failure.

Whether this would also improve renal function remains questionable.

\section{Low-Dose Theophylline}

Adenosine-mediated vasoconstriction appears to play a crucial role in the pathogenesis of asphyxic neonatal renal failure. Experimental studies ${ }^{22}$ and clinical trials have suggested a potential renoprotective effect of low-dose theophylline $(5 \mathrm{mg} / \mathrm{kg}$ ) in perinatal asphyxia and in idiopathic respiratory distress syndrome $(1 \mathrm{mg} / \mathrm{kg}){ }^{23-25}$ This beneficial effect has been ascribed to the adenosine antagonistic properties of theophylline. ${ }^{22}$

\section{Fluid Management in Neonates with Intrinsic Acute Renal Failure}

Oliguric neonates who fail to respond to these maneuvers (-Fig. 1) should be considered to have intrinsic renal failure and will require additional measures to prevent major homeostatic disturbances. In those neonates responding to the aforementioned measures by an increase in urine output, a progressive fall in the serum creatinine is observed. Persistence of elevated creatinine or increase in creatinine levels in the face of a good urine output suggests the presence of nonoliguric renal failure.

In oliguric neonates, fluid administration should be restricted to insensible water losses plus the ongoing renal and extrarenal losses. The insensible water losses in full-term neonates amount to $35 \mathrm{~mL} / \mathrm{kg} /$ day whereas in preterms this may vary from 60 to $70 \mathrm{~mL} / \mathrm{kg} /$ day. The fluid administered should be electrolyte-free and the concentration of glucose adjusted to deliver the adequate amount of glucose. Daily weight of the neonate is mandatory. In oligoanuric neonates a daily weight loss of $0.5 \%$ is expected and reflects appropriate fluid balance.

\section{Electrolyte Disorders}

\section{Hyponatremia}

When present in ARF, hyponatremia is dilutional in nature and should not be treated by giving sodium chloride. Freewater administration should be restricted instead to produce a gradual increase in the serum sodium concentration. However, when serum sodium level is less than $120 \mathrm{mmol} / \mathrm{L}$, it can give rise to cerebral edema that may manifest as lethargy, seizures, and apnea. In such situations, $3 \% \mathrm{NaCl}$ may be given intravenously at a slow rate of 5 to $6 \mathrm{~mL} / \mathrm{kg}$ over 2 to 4 hours. The amount of sodium required to correct the hyponatremia can be estimated as follows: $\mathrm{Na}$ needed $=\left(\right.$ desired $\mathrm{P}_{\mathrm{Na}}-$ actual $\left.\mathrm{P}_{\mathrm{Na}}\right) \times 0.8 \times \mathrm{BW}(\mathrm{kg})$, where $\mathrm{Na}$ is expressed in mmol and $\mathrm{P}_{\mathrm{Na}}$ in $\mathrm{mmol} / \mathrm{L}$; BW represents body weight and $0.8 \times$ BW represents total body water.

\section{Hyperkalemia}

Elevated potassium levels are fairly common in ARF. Mild hyperkalemia of 6 to $6.5 \mathrm{mmol} / \mathrm{L}$ without electrocardiographic (ECG) changes may require nothing more than the correction of coexisting metabolic acidosis. Higher levels of potassium or the presence of ECG changes require active cardioprotective measures that include intravenous calcium administration (0.5-1.0 mL/kg of $10 \%$ calcium gluconate, over 5 minutes under ECG surveillance), inhaled or parenteral salbutamol ( $4 \mu \mathrm{g} / \mathrm{kg}$ in $5 \mathrm{~mL}$ water or saline over 5 minutes), and glucose-insulin infusions. When the neonate is still passing urine, diuretics such as furosemide $(1 \mathrm{mg} / \mathrm{kg}$ ) can be tried. The use of potassium binding resins is not without risk in infants. It may cause gastric erosions when given orally and colonic ulcerations and fecal impaction when given rectally. ${ }^{26}$ They are thus best avoided in a sick neonate. Severe hyperkalemia (> $7.5 \mathrm{mmol} / \mathrm{L}$ ) and/or major ECG changes represent an indication for immediate dialysis.

\section{Hypocalcemia}

Hypocalcemia is common, but the ionic fraction may not be very low because of concomitant hypoalbuminemia and metabolic acidosis. When the hypocalcemia is symptomatic, intravenous calcium gluconate ( $10 \%$ calcium gluconate at a dose of $0.5-1.0 \mathrm{~mL} / \mathrm{kg}$ in 5 minutes under cardiac monitoring) needs to be given and repeated every 6 to 8 hours. Caution is required in the administration of IV calcium in the presence of hyperphosphatemia, as it may lead to soft tissue calcification and nephrocalcinosis.

\section{Hyperphosphatemia}

Hyperphosphatemia is common in neonates with renal failure. Calcium-containing phosphate binders such as calcium carbonate may be used although severe hyperphosphatemia is best treated with dialysis. Aluminum-containing phosphate binders are best avoided.

\section{Acidosis}

Mild metabolic acidosis is common in renal failure. When the plasma bicarbonate concentration falls less than $12 \mathrm{mmol} / \mathrm{L}$ and/or the plasma pH less than 7.20, correction of the acidosis is best achieved by adding sodium bicarbonate to the maintenance fluid.

\section{Convulsions}

Convulsions are the consequence of electrolyte imbalance or arterial hypertension. Symptomatic therapy is achieved by 
Table 2 Hypotensive agents in the neonate

\begin{tabular}{|l|l|l|l|l|}
\hline Agent & Starting dosage & Intervals & Maximum recommended & Route of administration \\
\hline Furosemide & $1 \mathrm{mg} / \mathrm{kg}$ & $\mathrm{q} 4-6 \mathrm{~h}$ & $5 \mathrm{mg} / \mathrm{kg} /$ dose & O/IV \\
\hline Hydrochlorothiazide & $1 \mathrm{mg} / \mathrm{kg}$ & $\mathrm{q} 8 \mathrm{~h}$ & $3 \mathrm{mg} / \mathrm{kg} /$ dose & $\mathrm{O}$ \\
\hline Propranolol & $0.25 \mathrm{mg} / \mathrm{kg} /$ dose & $\mathrm{q} 6-8 \mathrm{~h}$ & $5 \mathrm{mg} / \mathrm{kg} /$ dose & $\mathrm{O} / \mathrm{IV}$ \\
\hline Atenolol & $0.5 \mathrm{mg} / \mathrm{kg} /$ dose & $\mathrm{q} 12-24 \mathrm{~h}$ & $4 \mathrm{mg} / \mathrm{kg} /$ dose & $\mathrm{O}$ \\
\hline Labetalol & $0.5 \mathrm{mg} / \mathrm{kg} /$ dose & $\mathrm{q} 1-4 \mathrm{~h}$ & $2 \mathrm{mg} / \mathrm{kg} /$ dose & $\mathrm{IV}$ \\
\hline Sodium nitroprusside & $0.5 \mu \mathrm{gg} / \mathrm{min}$ & - & $6 \mu \mathrm{gg} / \mathrm{min}$ & $\mathrm{IV}$ \\
\hline Captopril & $0.1 \mathrm{mg} / \mathrm{kg} /$ dose & $\mathrm{q} 8-12 \mathrm{~h}$ & $0.5 \mathrm{mg} / \mathrm{kg} /$ dose & $\mathrm{O}$ \\
\hline Enalapril & $5 \mu \mathrm{gg} /$ dose & $\mathrm{q} 8-24 \mathrm{~h}$ & $20 \mu \mathrm{g} / \mathrm{kg} /$ dose & $\mathrm{IV}$ \\
\hline Nifedipine & $0.5 \mathrm{mg} / \mathrm{kg} /$ dose & $\mathrm{q} 4-6 \mathrm{~h}$ & $2 \mathrm{mg} / \mathrm{kg} /$ dose & $\mathrm{O}$ \\
\hline
\end{tabular}

Abbreviations: IV, intravenous; O, oral.

giving diazepam $(0.5 \mathrm{mg} / \mathrm{kg}$ IV or rectally), IV clonazepam ( 0.1 $\mathrm{mg} / \mathrm{kg}$ ), or IV phenobarbital (15-20 mg/kg).

\section{Hypertension}

Hypertension may occur as a result of volume overload as well as hyperreninemia. Severe or symptomatic hypertension is best treated with continuous intravenous infusion of nicardipine. Esmolol, enalaprilat, or sodium nitroprusside can be used with caution (-Table 2). ${ }^{14}$ The optimal oral therapy for newborns is not clearly known. ACEIs, notably captopril, have been used in neonatal hypertension. However, their use in the context of neonatal renal failure is risky as they may worsen the condition. If necessary, they should be used cautiously in small doses. Calcium channel blockers can be used as first-line drugs. $\beta$ Adrenergic blockers should be used with caution and are best avoided in babies with coexisting respiratory problems. In these babies diuretics may form a good adjunct.

\section{Sepsis}

Severe infection is a common cause of death in neonates with ARF. Adequate intravenous antibiotherapy is essential. The dosage of drugs excreted mainly by the kidney (aminoglycosides, vancomycin) must be adapted to the severity of renal failure (-Table 3 ). When possible, monitoring of plasma concentrations is recommended.

\section{Nutrition}

Nutritional inadequacy is an important contributor to neonatal mortality. When feasible, enteral nutrition should consist of appropriate formulas that are calorically dense with a low electrolyte content. Neonates require $120 \mathrm{kcal} / \mathrm{kg} / \mathrm{day}$. Protein restriction should be avoided in neonates. When enteral nutrition is not feasible, parenteral nutrition may have been used. High concentrations of glucose need to be given to provide the required nonprotein calories.

\section{Acute Renal Replacement Therapy}

Renal replacement therapy (RRT) is indicated when the renal failure produces serious derangements such as fluid overload, severe hyperkalemia, uncontrolled metabolic acidosis, hyperphosphatemia, or hyponatremia unresponsive to fluid restriction. ${ }^{27}$ RRT with ultrafiltration may also be required to create enough fluid space to allow the administration of the necessary medications, blood products, and nutrition that the child may need.

\section{Peritoneal Dialysis}

Peritoneal dialysis is the most common and widely used option for RRT in this age group. ${ }^{4,27}$ It is easily instituted even in the very tiny infant with either percutaneous bedside placement of a stiff catheter or surgical placement of a soft Tenckhoff catheter. Acutely ill babies on ventilator may not tolerate large intraperitoneal volumes. Small volumes with short dwelling times may suffice to tackle the acute lifethreatening problems. Bicarbonate dialysis is needed in children with liver dysfunction or advanced sepsis as use of lactate-based dialysis fluid may lead to worsening of acidosis in these babies. The presence of intra-abdominal pathology may preclude the use of the peritoneum for dialysis.

Table 3 Drugs requiring dose adjustment when GFR is compromised

\begin{tabular}{|l|}
\hline Antibiotics \\
\hline Aminoglycosides (amikacin, gentamicin, tobramycin) \\
\hline Amoxicillin, amoxicillin-clavulanic acid \\
\hline Cephalosporin (cefixime, cefotaxime, ceftazidime) \\
\hline Cotrimoxazole \\
\hline Ticarcillin \\
\hline Vancomycin \\
\hline Antifungal agents \\
\hline Fluconazole \\
\hline Cardiac drugs \\
\hline Digoxin \\
\hline
\end{tabular}

Abbreviation: GFR, glomerular filtration rate. 


\section{Hemodialysis}

Hemodialysis is infrequently used in this age group and can be considered only in hemodynamically stable babies. In neonates, it requires the availability of suitably small dialyzers and tubings. Blood or albumin priming of the lines and filter is usually needed. It can be done only in units where sufficient technical expertise is available.

\section{Continuous Venovenous Hemofiltration}

Continuous venovenous hemofiltration is a modality that can be used in sick neonates requiring renal replacement. It allows greater fluid removal, better hemodynamic stability, and better nutrition. Its use in critically ill children with renal failure is increasing steadily with improving results.

\section{Outcome}

Despite major advances, the mortality in neonates with ARF is fairly high and ranges from 45 to $60 \% .{ }^{28-31}$ Neonates with prerenal failure have a better outcome than those with intrinsic renal failure. The worst outcome is seen in babies with intrinsic renal failure in the context of multiple organ dysfunction. As the development of renal failure is a reflection of the severity of illness, it is not surprising that the mortality is so high. Babies with nonoliguric renal failure have a much better outcome than those with oligoanuric renal failure. $^{28}$

Following recovery from the ARF, residual renal dysfunction may be seen in more than half the babies without an underlying congenital uropathy. ${ }^{13}$ Incomplete recovery is present in the neonates who have suffered cortical necrosis. Babies with in utero exposure to NSAIDs, ACEIs, or ARBs have a poor renal outcome, and are likely to have persistent irreversible renal failure. Long-term follow-up of extremely low-birth-weight infants with neonatal renal failure has shown that nearly $45 \%$ of the children show a decrease in GFR over time. Urine proteins/creatinine ratio of greater than $70 \mathrm{~g} / \mathrm{mol}$ creatinine $(0.6 \mathrm{mg} / \mathrm{mg}$ creatinine), and serum creatinine greater than $55 \mu \mathrm{mol} / \mathrm{L}(6 \mathrm{mg} / \mathrm{L})$ at 1 year of age were predictors of a poor prognosis for long-term renal function. ${ }^{32}$

\section{Conclusion}

When recovery from ARF is incomplete, the occurrence of chronic renal failure is associated with significant morbidity, such as growth retardation and renal osteodystrophy. When renal replacement therapy is considered, decisions must be discussed with the family and an expert ethical committee, keeping in mind the difficult global management of renal failure in the first years of life.

\section{References}

1 Guignard JP. Glomerular filtration rate in neonates. In: Oh W, Guignard JP, Baumgart S eds. Nephrology and Fluid/Electrolyte Physiology: Neonatology Questions and Controversies. Philadelphia, PA: Saunders Elsevier; 2012:117-135
2 Vieux R, Hascoet JM, Merdariu D, Fresson J, Guillemin F. Glomerular filtration rate reference values in very preterm infants. Pediatrics 2010;125(5):e1186-e1192

3 Guignard JP, Drukker A. Why do newborns have elevated plasma creatinine levels? Pediatrics 1999;103(4):e49

4 Andreoli SP. Kidney injury in the neonate. In: Oh W, Guignard JP, Baumgart S eds. Nephrology and Fluid/Electrolyte Physiology: Neonatology Questions and Controversies. Philadelphia, PA: Saunders Elsevier; 2012:285-303

5 Rodriguez MM, Gomez A, Abitbol C, Chandar J, Montané B, Zilleruelo G. Comparative renal histomorphometry: a case study of oligonephropathy of prematurity. Pediatr Nephrol 2005;20(7):945-949

6 Gouyon JB, Guignard JP. Management of acute renal failure in newborns. Pediatr Nephrol 2000;14(10-11):1037-1044

7 Tóth-Heyn P, Drukker A, Guignard JP. The stressed neonatal kidney: from pathophysiology to clinical management of neonatal vasomotor nephropathy. Pediatr Nephrol 2000;14(3):227-239

8 Guignard JP, Gouyon JB. Adverse effects of drugs on the immature kidney. Biol Neonate 1988;53(4):243-252

9 Durkan AM, Alexander RT. Acute kidney injury post neonatal asphyxia. J Pediatr 2011;158(2, Suppl)e29-e33

10 Guignard J-P. The adverse renal effects of prostaglandin-synthesis inhibitors in the newborn rabbit. Semin Perinatol 2002;26(6): 398-405

11 Barr M Jr. Teratogen update: angiotensin-converting enzyme inhibitors. Teratology 1994;50(6):399-409

12 Kuiper JW, Groeneveld AB, Slutsky AS, Plötz FB. Mechanical ventilation and acute renal failure. Crit Care Med 2005;33(6): $1408-1415$

13 Sanna-Cherchi S, Ravani P, Corbani V, et al. Renal outcome in patients with congenital anomalies of the kidney and urinary tract. Kidney Int 2009;76(5):528-533

14 Flynn JT. Hypertension in the neonatal period. Curr Opin Pediatr 2012;24(2):197-204

15 Karlowicz MG, Adelman RD. Nonoliguric and oliguric acute renal failure in asphyxiated term neonates. Pediatr Nephrol 1995;9(6): 718-722

16 Parikh CR, Devarajan P. New biomarkers of acute kidney injury. Crit Care Med 2008;36(4, Suppl)S159-S165

17 Askenazi DJ, Koralkar R, Hundley HE, et al. Urine biomarkers predict acute kidney injury in newborns. J Pediatr 2012;161(2): 270-5.e 1

18 Seri I. Hydrocortisone is effective in treatment of vasopressorresistant hypotension in very low birth weight neonates. J Pediatr 2006;149(3):422-423

19 Seri I. Cardiovascular, renal, and endocrine actions of dopamine in neonates and children. J Pediatr 1995;126(3):333-344

20 Bellomo R, Chapman M, Finfer S, Hickling K, Myburgh J; Australian and New Zealand Intensive Care Society (ANZICS) Clinical Trials Group. Low-dose dopamine in patients with early renal dysfunction: a placebo-controlled randomised trial. Lancet 2000; 356(9248):2139-2143

21 Guignard JP. Use of diuretics in the newborn. In: Oh W, Guignard JP, Baumgart S eds. Nephrology and Fluid/Electrolyte Physiology: Neonatology Questions and Controversies. Philadelphia, PA: Saunders Elsevier; 2012:233-250

22 Gouyon JB, Guignard JP. Theophylline prevents the hypoxemiainduced renal hemodynamic changes in rabbits. Kidney Int 1988; 33(6):1078-1083

23 Jenik AG, Ceriani Cernadas JM, Gorenstein A, et al. A randomized, double-blind, placebo-controlled trial of the effects of prophylactic theophylline on renal function in term neonates with perinatal asphyxia. Pediatrics 2000;105(4):E45

24 Cattarelli D, Spandrio M, Gasparoni A, et al. A randomized double blind placebo trial of the effect of theophylline in prevention of vasomotor nephropathy in very preterm neonates with respiratory distress syndrome. Arch Dis Child Fetal Neonatal Ed 2006;91: F80-F84 
25 Al-Wassia H, Alshaikh B, Sauve R. Prophylactic theophylline for the prevention of severe renal dysfunction in term and post-term neonates with perinatal asphyxia: a systematic review and metaanalysis of randomized controlled trials. J Perinatol 2013;33(4): 271-277

26 Ohlsson A, Hosking M. Complications following oral administration of exchange resins in extremely low-birth-weight infants. Eur J Pediatr 1987;146(6):571-574

27 Coulthard MG, Vernon B. Managing acute renal failure in very low birthweight infants. Arch Dis Child Fetal Neonatal Ed 1995;73(3): F187-F192

28 Otukesh H, Hoseini R, Hooman N, Chalian M, Chalian H, Tabarroki A. Prognosis of acute renal failure in children. Pediatr Nephrol 2006;21(12):1873-1878
29 Koralkar R, Ambalavanan N, Levitan EB, McGwin G, Goldstein S, Askenazi D. Acute kidney injury reduces survival in very low birth weight infants. Pediatr Res 2011;69(4):354-358

30 Vachvanichsanong P, McNeil E, Dissaneevate S, Dissaneewate P, Chanvitan P, Janjindamai W. Neonatal acute kidney injury in a tertiary center in a developing country. Nephrol Dial Transplant 2012;27(3):973-977

31 Momtaz HE, Sabzehei MK, Rasuli B, Torabian S. The main etiologies of acute kidney injury in the newborns hospitalized in the neonatal intensive care unit. J Clin Neonatol 2014;3(2): 99-102

32 Abbitol CL, Bauer CR, Montané B, Chandar J, Duara S, Ziruello G. Long-term follow-up of extremely low birth weight infants with neonatal renal failure. Pediatr Nephrol 2003;18(9):887-893 